\title{
Dialkyl Succinates and Adipates as Alternative Plasticizers-Even More Efficient Synthesis
}

\author{
Natalia Barteczko ${ }^{1}{ }^{\circledR}$, Justyna Więcławik ${ }^{1}$, Anna Tracz ${ }^{2}$, Ewa Pankalla ${ }^{2}$, Karol Erfurt $^{1}{ }^{\circledR}$, Piotr Latos ${ }^{1}{ }^{\circledR}$, \\ Sławomir Boncel ${ }^{3, *(D)}$, Karolina Matuszek ${ }^{4}$ (D) and Anna Chrobok ${ }^{1, *(D)}$ \\ 1 Department of Chemical Organic Technology and Petrochemistry, Silesian University of Technology, \\ Krzywoustego 4, 44-100 Gliwice, Poland; Natalia.Barteczko@polsl.pl (N.B.); \\ Justyna.Wieclawik@polsl.pl (J.W.); Karol.Erfurt@polsl.pl (K.E.); Piotr.Latos@polsl.pl (P.L.) \\ 2 Grupa Azoty Zakłady Azotowe Kędzierzyn, S.A., Mostowa 30A, 47-220 Kędzierzyn-Koźle, Poland; \\ Anna.Tracz@grupaazoty.pl (A.T.); Ewa.Pankalla@grupaazoty.pl (E.P.) \\ 3 Department of Organic Chemistry, Bioorganic Chemistry and Biotechnology, Faculty of Chemistry, \\ Silesian University of Technology, Krzywoustego 4, 44-100 Gliwice, Poland \\ 4 School of Chemistry, Monash University, Clayton, VIC 3800, Australia; Karolina.Matuszek@monash.edu \\ * Correspondence: Slawomir.Boncel@polsl.pl (S.B.); Anna.Chrobok@polsl.pl (A.C.); \\ Tel.: +48-32-237-12-72 (S.B.); +48-32-237-20-14 (A.C.)
}

Citation: Barteczko, N.; Więcławik, J.; Tracz, A.; Pankalla, E.; Erfurt, K.; Latos, P.; Boncel, S.; Matuszek, K.; Chrobok, A. Dialkyl Succinates and Adipates as Alternative Plasticizers-Even More Efficient Synthesis. Materials 2021, 14, 6219. https://doi.org/10.3390/ma14206219

Academic Editor: Marek Hebda

Received: 24 August 2021

Accepted: 13 October 2021

Published: 19 October 2021

Publisher's Note: MDPI stays neutral with regard to jurisdictional claims in published maps and institutional affiliations.

Copyright: (c) 2021 by the authors. Licensee MDPI, Basel, Switzerland. This article is an open access article distributed under the terms and conditions of the Creative Commons Attribution (CC BY) license (https:// creativecommons.org/licenses/by/ $4.0 /)$.

\begin{abstract}
As a result of strict regulations of phthalate plasticizers, alternative non-phthalate forms are desired and increasingly used. This work presents a synthetic method for alternative plasticizers (dialkyl succinates and adipates) via esterification of succinic and adipic acid with alcohols: butan1-ol and 2-ethylhexan-1-ol. Ionic liquids were synthesized by the reaction of triethylamine with over-equimolar (1:2.7) amounts of sulfuric(VI) acid, which were used as an acidic catalyst and solvent. The two-phase liquid-liquid system was formed during the reaction due to immiscibility of the esters with the ionic liquid. This phenomenon is a driving force of this process, shifting the equilibrium toward the product formation. As a result, dialkyl succinates and adipates were obtained in high yields (99\%) and selectivities (>99\%), under mild reaction conditions at $70-80{ }^{\circ} \mathrm{C}$ and using a $4: 1$ molar ratio of alcohol to acid and $15 \mathrm{~mol} \%$ of catalyst. The catalyst was recycled 10 times without any loss of activity. This alternative method is highly competitive: it involves a simple procedure for product isolation as well as a high yield and purity of the resulting esters. These advantages make this method sustainable and promising for industrial applications.
\end{abstract}

Keywords: plasticizers; succinate esters; adipates esters; ionic liquids; acidic catalysis; esterification; solvents

\section{Introduction}

Until recently, the most popular and produced plasticizers were phthalates, in particular bis (2-ethylhexyl) phthalate, di-n-butyl phthalate, di(isononyl) phthalate, di(isodecyl) phthalate and di- $n$-octyl phthalate. In 2015, the European Union introduced legal regulations that limited the use of phthalates due to their toxicity. Similar regulations limiting the use of phthalates are respected in North America, while in South America, India and China their use is not currently regulated by legal standards [1].

Many alternative non-phthalate plasticizers are now used including alkyl esters such as: terephthalates, adipates, succinates, trimellitates, benzoates, phosphates, sebacates, citrates, maleates, fumarates and epoxidized vegetable oils (soybean, rapeseed) [2-4]. Among them, the most popular are dialkyl succinates such as dioctyl succinate (DOS), dihexyl succinate, dibutyl succinate (DBS) and diethyl succinate. Succinate-based plasticizers (80-90\% of world production) are most often used for poly(vinyl chloride) (PVC), which is considered to be the most plasticized polymer, as well as for other polymers: polyacrylates, polyvinyl acetate, polyolefins, polyurethanes and natural rubber [5-7]. Dialkyl succinates with longer alkyl chains, e.g., DOS, are the most effective plasticizers with similar or even 
better plasticizing properties than phthalate esters, having a high compatibility with the polymers that allows a high plasticization efficiency. Succinates with shorter alkyl chains achieve similar plasticizing properties to phthalates but require higher concentrations. Alkyl succinates originate from biomass conversion, are stable, biodegradable and are very often used in combination with epoxidized soybean oil (ESO). DOS is used in a wide variety of products including cosmetics and personal care products, adhesives and sealants, coating products, inks and toners and lubricants. It is also used as an additive to detergents, in car wash and care liquids, paints, fragrances and air fresheners [8,9].

Alcohols with the same alkyl chain length as phthalate esters can be also esterified with adipic acid to obtain adipate plasticizers, e.g., esterification of 2-ethylhexan-1-ol with adipic acid gives bis (2-ethylhexyl) adipate (DEHA). Adipic acid esters are widely used as PVC plasticizers due to their good performance at low temperatures and their lower viscosity than phthalate plasticizers. The most frequently used adipates have chain lengths up to $\mathrm{C} 10$, with longer chains becoming physicochemically incompatible with many polymers [10]. Additionally, adipates show greater variability and a higher degree of migration than phthalates and are more expensive due to their specialized use. The group of adipate plasticizers is characterized by a significant improvement in the flexibility of the material at low temperatures, which is due to the linear structure of the molecule and results in a lower viscosity of adipates as compared to phthalates and other plasticizers [11,12]. Moreover, Hocevar et al. recently reported that adipic acid can be directly produced from bio-based sources [13]. They presented the first heterogeneous catalytic process for converting an aldaric acid into muconic and adipic acid.

The non-phthalate plasticizers described above are produced via an esterification reaction which is carried out in the presence of acidic catalysts at high temperatures (above $100{ }^{\circ} \mathrm{C}$ ), which can cause undesirable degradation reactions of alcohols to olefins or ethers. Additionally, the water-alcohol azeotrope needs to be distilled off to shift the equilibrium towards the product formation at a temperature of about $185^{\circ} \mathrm{C}$. An important issue, which is an object of extensive investigation in the esterification processes, is to manipulate the equilibrium of the reaction. An excess of the cheaper reagent or methods for the effective product isolation from the reaction mixture are the most often-used tools [14].

For example, di- $n$-butyl adipate was synthesised in the presence of MOFs ( $1 \mathrm{~mol} \%)$ as a catalyst with a $99.9 \%$ yield after $60 \mathrm{~min}$ at $190{ }^{\circ} \mathrm{C}$, using a 10 -fold excess of alcohol in relation to the acid [15].

Di- $n$-butyl succinate was obtained with $91.6 \%$ yield in the presence of Lewis acid sites of $\mathrm{Mg}^{2+}$-modified polystyrene sulfonic acid resin at $120{ }^{\circ} \mathrm{C}$ after $60 \mathrm{~min}$, using a 3-fold excess of 2-ethylhexan-1-ol to succinic acid [16].

Di(2-ethylhexyl)adipate can be obtained in an enzymatic esterification process catalysed by Candida Antarctica lipase B. This method allows for the achievement of almost $100 \%$ yield of the product when the process is carried out at a temperature of $50{ }^{\circ} \mathrm{C}$ for 180 min under a reduced pressure of $6.7 \mathrm{kPa}$ [17].

The synthesis of di(2-ethylhexyl) succinate in the presence of a heterogeneous nano$\mathrm{SO}_{4}{ }^{2-} / \mathrm{TiO}_{2}$ catalyst was also described. The product, with a $97 \%$ yield, was obtained at $160{ }^{\circ} \mathrm{C}$ after $120 \mathrm{~min}$ of rection [18].

Another example of acidic catalyst activated with bentonite was used for the synthesis of di-n-butyl succinate using 3.5-fold excess of alcohol at $130{ }^{\circ} \mathrm{C}$. Under these conditions, the product was obtained after $180 \mathrm{~min}$ with $98.5 \%$ yield [19].

However, these methods are expensive and energy-consuming. A more novel approach adopts acidic ionic liquids (ILs) as catalysts and solvents. In this system, reagents and water are dissolved in the ionic liquid phase and the ester forms the second liquid phase. A continuous removal of the ester to the second phase shifts the equilibrium towards the ester formation [20,21].

Lewis acidic ILs obtained in the reaction of 1-butylpyridinium chloride and aluminium chloride were used for the initial esterification studies [22]. Due to the low levels of stability of Lewis ILs when in the presence of moisture, they cannot be applied for this process. 
On the other hand, Brønsted acidic ILs are stable in the presence of water and they have been successfully used in esterification reactions. Brønsted acidic functionality in ILs can be introduced to cation, anion, or both, bearing: (a) a proton on the quaternary nitrogen atom of the cation; (b) a protonated acidic group on the cation alkyl chain $\left(-\mathrm{SO}_{3} \mathrm{H}\right)$; (c) an available proton on the anion $\left(\left[\mathrm{HSO}_{4}\right]^{-}\right)$[23-26]. Simple synthesis of Brønsted acidic ILs, based on the proton transfer between strong inorganic acids $\left(\mathrm{H}_{2} \mathrm{SO}_{4}, \mathrm{HNO}_{3}, \mathrm{CF}_{3} \mathrm{COOH}\right)$ and an $\mathrm{N}$-base such as imidazole, pyrrolidine, piperidine or trialkylamine, makes this process not only effective but also economically viable [27]. Moreover, the structure of Brønsted acidic ILs can be tuned to find the proper acidity of the catalyst. For example, sulphuric(VI) acid can be used in various molar ratios, $\chi_{\mathrm{H} 2 \mathrm{SO} 4}=0.50,0.67$ or 0.75 in regard to the base. In our previous work, we demonstrated that the Gutmann acceptor number (AN) value measured for protic ILs based on 1-methylimidazole, for $\chi_{\mathrm{H} 2 \mathrm{SO} 4}=0.50$ ([Hmim] $\left.\left[\left(\mathrm{HSO}_{4}\right)\right]\right)$, showing rather medium acidity $(\mathrm{AN}=73.3)$. In this case, the acidity arises from the presence of the labile proton at the cation as well as the hydrogensulfate anion [28], whereas ILs obtained with an excess of $\mathrm{H}_{2} \mathrm{SO}_{4}\left(\chi_{\mathrm{H} 2 \mathrm{SO}}=0.67\right.$ or 0.75$)$ exhibit high acidity expressed by $\mathrm{AN}=117-122$ [28], similar to the acidity of strong acids such as $\mathrm{CF}_{3} \mathrm{COOH}$ $(\mathrm{AN}=105.5)$ and $\mathrm{CF}_{3} \mathrm{SO}_{3} \mathrm{H}(\mathrm{AN}=129.1)$ [29]. Synthesis of these more acidic ILs leads to the formation of a hydrogen-bonded network of $\mathrm{H}_{2} \mathrm{SO}_{4}$ molecules and $\left[\mathrm{HSO}_{4}\right]^{-}$anions in an anion structure. The resulting ILs were used as both the acidic catalysts and as the solvent for the esterification of levulinic, terephthalic and lactic acids [30-32], as well as for the synthesis of $\varepsilon$-caprolactam [33].

Herein, we present the efficient method for the synthesis of dialkyl (di- $n$-butyl and dioctyl) succinates and adipates in the presence of low-cost Brønsted acidic ILs. This work contributes to the development of sustainable and environmentally-friendly processes for the production of green plasticizers.

\section{Materials and Methods}

\subsection{Materials}

Triethylamine (>99\%), sulphuric(VI) acid (95\%) and $n$-decane (>99\%) were purchased from Sigma-Aldrich (Merck, Darmstadt, Germany). Adipic acid was purchased from BASF SE (Ludwigshafen am Rhein, Germany). Succinic acid (99\%) was purchased form Acros Organic (Thermo Fisher Scientific, Waltham, MA, USA). Butan-1-ol and 2-ethylhexan-1-ol were produced at the plants of Grupa Azoty Zakłady Azotowe Kędzierzyn S.A. Deuterated solvents, e.g., dimethyl sulfoxide-d6 (99.8\%) and chloroform-d (99.8\%), were purchased from Sigma-Aldrich (Merck, Darmstadt, Germany).

\subsection{Methods}

GC analyses were performed on a Shimadzu GC-2010 Plus (Kyoto, Japan) (carrier gas-helium) with an oven temperature program: start at $80^{\circ} \mathrm{C}$ isothermal for $1 \mathrm{~min}$, then reach $300{ }^{\circ} \mathrm{C}$ with a heating rate of $40{ }^{\circ} \mathrm{C} / \mathrm{min}$ and then $5 \mathrm{~min}$ at $300^{\circ} \mathrm{C}$ isothermal. The Shimadzu GC-2010 Plus was equipped with a flame ionization detector (FID) and a Zebron ZB-5MSi column (30 $\mathrm{m} \times 0.25 \mathrm{~mm} 0.25 \mu \mathrm{m}$ film).

The NMR spectra of the products were recorded using a Varian 400 spectrometer (Palo Alto, CA, USA.) at the following operating frequencies: ${ }^{1} \mathrm{H} 400 \mathrm{MHz}$ and ${ }^{13} \mathrm{C} 100 \mathrm{MHz}$. Chemical shifts are reported as parts per million (ppm) in reference to tetramethylsilane (TMS) for $0.020 \mathrm{~g}$ of the sample dissolved in $0.5 \mathrm{~mL}$ of deuterated solvent, e.g., DMSO-d6 or $\mathrm{CDCl}_{3}$.

\subsection{Synthesis}

Ionic liquids: three ILs with different molar ratios of amine to $\mathrm{H}_{2} \mathrm{SO}_{4}(1: 3,1: 2.7$ and 1:2) were prepared, later called IL 3.0, IL 2.7 and IL 2.0, respectively. Triethylamine (25.30 g, $0.25 \mathrm{~mol}$ ) and the water solution (water $10 \mathrm{wt} . \%$ in regard to acid and base) of sulphuric(VI) acid (IL 3.0: 74.2 g; IL 2.7: $66.8 \mathrm{~g}$; IL 2.0: $49.5 \mathrm{~g}$ ) were slowly added dropwise to the batch jacket reactor $(250 \mathrm{~mL})$ equipped with a thermometer, a condenser and a mechanical stirrer, 
keeping the temperature at $40{ }^{\circ} \mathrm{C}(7 \mathrm{~Hz}, 20 \mathrm{~min})$. Next, the reaction mixture was stirred for $60 \mathrm{~min}$ at $25^{\circ} \mathrm{C}$. Subsequently, water was evaporated and ILs were dried on high vacuum $\left(80^{\circ} \mathrm{C}, 10^{-2} \mathrm{mbar}, 720 \mathrm{~min}\right)$. The obtained ILs were colourless liquids with a $98 \%$ yield. ${ }^{1} \mathrm{H}$ NMR (400 MHz, DMSO) $\delta 8.95$ (s, 1H), 7.51 (bs, 5H), 3.07 (q, 6H, J = 6.4 Hz), 1.15 (t, 9H, $\mathrm{J}=7.9 \mathrm{~Hz}) .{ }^{13} \mathrm{C}$ NMR $(100 \mathrm{MHz}, \mathrm{DMSO}) \delta 48.02,12.20$.

Succinate and adipate esters: IL 2.7 (0.75-0.92 g, 2.10-2.50 mmol, $15 \mathrm{~mol} \%)$, alcohol (10.69-13.23 g, 0.08-0.10 mol) and acid (2.00 g, 0.014-0.02 mol, molar ratio of acid to alcohol: 1:4) were mixed at $70{ }^{\circ} \mathrm{C}$ for $240 \mathrm{~min}$ in a round-bottom reactor $(25 \mathrm{~mL})$, equipped with a reflux condenser, a temperature probe, an oil bath and a magnetic stirrer. At the end of the process, the phases were separated. Hexane $(20 \mathrm{~mL})$ was added to the upper phase, which was then extracted with water $(3 \times 20 \mathrm{~mL})$, washed with a saturated aqueous solution of $\mathrm{NaHCO}_{3}(10 \mathrm{~mL})$ to remove the traces of acidic IL and, finally, concentrated using a rotary evaporator. Next the alcohol was removed by vacuum distillation at $63-65{ }^{\circ} \mathrm{C}(10 \mathrm{mmHg})$ for 2-ethylhexan-1-ol and $115-118{ }^{\circ} \mathrm{C}(760 \mathrm{mmHg})$ for buthan-1-ol.

2-ethylhexyl succinate was obtained in $82 \%$ yield $(5.68 \mathrm{~g})$ as a colourless liquid; ${ }^{1} \mathrm{H} \mathrm{NMR}\left(400 \mathrm{MHz} \mathrm{CDCl}_{3}\right) \delta 4.01(\mathrm{~m}, 4 \mathrm{H}), 2.63(\mathrm{~s}, 4 \mathrm{H}), 1.55(\mathrm{~m}, 2 \mathrm{H}), 1.32(\mathrm{~m}, 12 \mathrm{H}), 0.89$ $(\mathrm{m}, 12 \mathrm{H})$.

Di- $n$-butyl succinate was obtained in $83 \%$ yield $(3.98 \mathrm{~g})$ as a colourless liquid. ${ }^{1} \mathrm{H}$ NMR $\left(400 \mathrm{MHz}, \mathrm{CDCl}_{3}\right) \delta 4.09(\mathrm{t}, 4 \mathrm{H}, \mathrm{J}=6.69 \mathrm{~Hz}), 2.62(\mathrm{~s}, 4 \mathrm{H}), 1.61\left(\mathrm{dt}, 4 \mathrm{H}, \mathrm{J}_{1}=6.77 \mathrm{~Hz}\right.$, $\left.\mathrm{J}_{2}=14.66 \mathrm{~Hz}\right), 1.38(\mathrm{~m}, 4 \mathrm{H}), 0.93(\mathrm{t}, 6 \mathrm{H}, \mathrm{J}=7.38 \mathrm{~Hz})$.

2-Ethylhexyl adipate was obtained in $91 \%$ yield $(4.93 \mathrm{~g})$ of as a colourless liquid. ${ }^{1} \mathrm{H} \mathrm{NMR}\left(400 \mathrm{MHz}, \mathrm{CDCl}_{3}\right) \delta 3.99(\mathrm{~m}, 4 \mathrm{H}), 2.33(\mathrm{~s}, 4 \mathrm{H}), 1.67(\mathrm{~m}, 4 \mathrm{H}), 1.56(\mathrm{~m}, 2 \mathrm{H}), 1.53(\mathrm{~m}, 4 \mathrm{H})$, $1.33(\mathrm{~m}, 12 \mathrm{H}), 0.89(\mathrm{~m}, 12 \mathrm{H})$.

Di- $n$-butyl adipate was obtained in $89 \%$ yield $(3.56 \mathrm{~g})$ as a colourless liquid. ${ }^{1} \mathrm{H}$ NMR $\left(400 \mathrm{MHz} \mathrm{CDCl}_{3}\right) \delta 4.05(\mathrm{~m}, 4 \mathrm{H}), 2.33(\mathrm{~m}, 4 \mathrm{H}), 1.59(\mathrm{~m}, 8 \mathrm{H}), 1.35(\mathrm{~m}, 4 \mathrm{H}), 0.89(\mathrm{~m}, 6 \mathrm{H})$.

\subsection{Esterification Procedure}

To monitor the progress of esterification reactions, a series of experiments was performed. The experiments were carried out in a round-bottom reactor $(25 \mathrm{~mL})$ equipped with a reflux condenser, a temperature probe, an oil bath and a magnetic stirrer. Depending on the experiment, the appropriate amounts of acid (2.00 g), alcohol (2:1-5:1 molar ratio vs. acid) and IL (5-30 mol\% vs. acid) were placed in the reactor and the following conditions were applied: temperature between $40-80{ }^{\circ} \mathrm{C}$ for $60-240 \mathrm{~min}$, stirring at $1000 \mathrm{rpm}$. The studies were carried out using different ILs (IL 3.0; IL 2.7 and IL 2.0). After the reaction mixture was homogenized with $4 \mathrm{~mL}$ acetonitrile and $0.3 \mathrm{~g}$ of $n$-decane was added as the internal standard, $40 \mu \mathrm{L}$ of the solution was withdrawn, dissolved in $1.5 \mathrm{~mL}$ of acetonitrile and analysed using GC-FID. Yield and conversion were calculated based on the calibration curve prepared for the main product. The experiments were performed in triplicate and the errors were calculated as standard deviations.

\subsection{Recycling Study}

A recycling study was performed to confirm stability and reusability of ILs in the synthesis of both DEHS and DEHA. The reaction was carried out in a round-bottom reactor (25 mL), equipped with a reflux condenser, a temperature probe, an oil bath and a magnetic stirrer. Alcohol (butan-1-ol and 2-ethylhexan-1-ol; $4 \mathrm{~mol}$ ), acid (succinic acid and adipic acid; $1 \mathrm{~mol})$ and IL 2.7 (15 mol\%) were placed in a reactor and the reaction was carried out at $80^{\circ} \mathrm{C}, 17 \mathrm{~Hz}$ with reaction time of $240 \mathrm{~min}$. After the reaction, the IL was isolated via phase separation, washed with water, dried on the rotary evaporator $\left(80^{\circ} \mathrm{C}, 1-2 \mathrm{mbar}\right.$, $720 \mathrm{~min}$ ) and used for another cycle of reaction. The upper phase was dissolved in $4 \mathrm{~mL}$ of acetonitrile, $0.3 \mathrm{~g}$ of $n$-decane was added as the internal standard and then $40 \mu \mathrm{L}$ of that solution was withdrawn, dissolved in $1.5 \mathrm{~mL}$ of acetonitrile and analysed on GC-FID. Yield and conversion were calculated based on the calibration curve prepared for the main product. GC samples were analysed in triplicate and the errors were calculated as standard deviations. 


\section{Results}

In preliminary studies, the suitable structure of ILs for the synthesis of dialkyl succinates and adipates was selected. Low-cost triethylamine and $\mathrm{H}_{2} \mathrm{SO}_{4}$ were chosen for the studies. Brønsted acidic ILs for the indicial tests were synthesised as described in the experimental section in the following molar ratios: 1:2.0, 1:2.7 and 1:3.0. Water was added to the reaction mixture to enable heat removal from the exothermic acid-base reaction [31,32]. After drying, the obtained ILs (IL 2.0; 2.7 and 3.0) were colourless liquids.

Next, ILs 2.0, 2.7 and 3.0 (15 mol\%/mol succinic acid) were used for the model esterification of succinic acid and butan-1-ol as well as 2-ethylhexan-1-ol (molar ratio 1:4) at $70{ }^{\circ} \mathrm{C}$ (Figure 1; Scheme 1). The reaction progress was monitored with GC-FID. In each case the full conversion of acid and $99 \pm 2 \%$ of selectivity was observed with no traces of monoalkylated ester. During the reaction course, the formation of the second ester phase was observed and this facilitates the reaction progress, shifting the equilibrium towards the ester formation (Scheme 2).

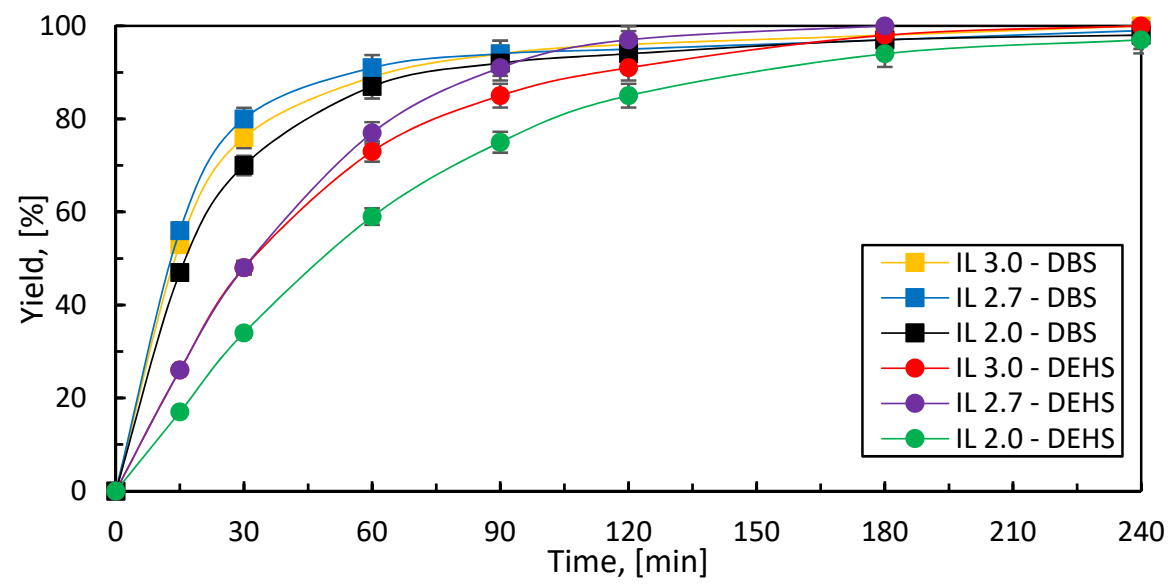

Figure 1. The influence of the IL composition on the esterification of succinic acid with butan-1-ol and 2-etylhexan-1-ol. Reaction conditions: alcohol 4 mol; succinic acid 1 mol; IL 2.7 (15 mol\%/mol succinic acid $(0.0025 \mathrm{~mol})) ; 70{ }^{\circ} \mathrm{C} ; 17 \mathrm{~Hz}$.

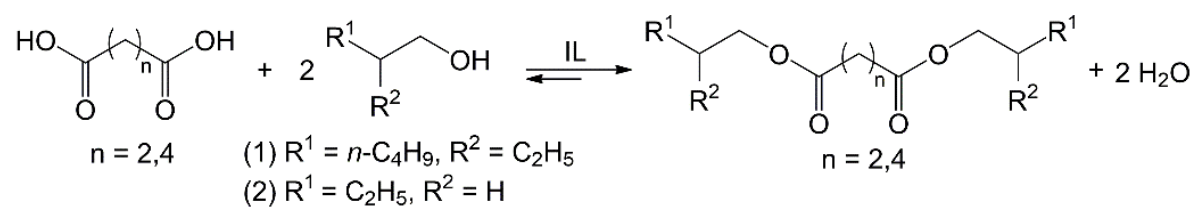

Scheme 1. The esterification of succinic and adipic acids with butan-1-ol and 2-ethylhexan-1-ol.

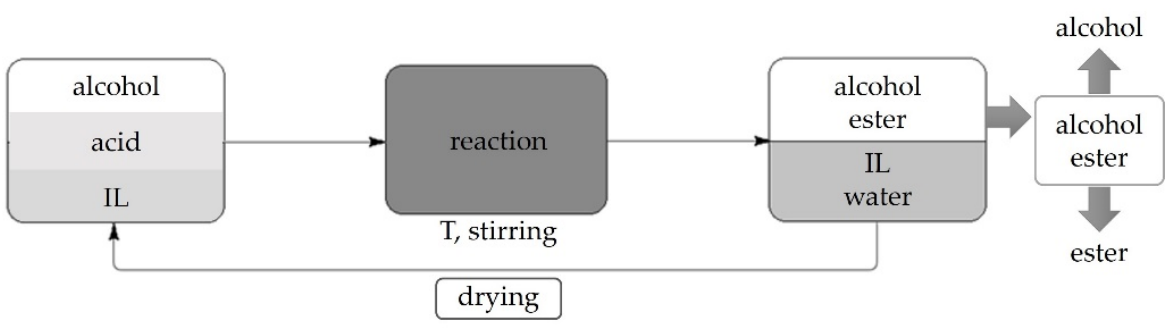

Scheme 2. Overview of the esterification process adapted in this work.

In the first step, alcohol, acid and ILs are placed in the reactor. Alcohol and acid are partially miscible with IL. The increased temperature, vigorous mixing and ester/IL phase separation drives the esterification reaction. After completion of the reaction, two phases are separated. The IL phase after drying yields pure ILs that can be used in the next 
process. The upper layer is further processed to obtain the final ester. Distilled alcohol can be reused.

The obtained results showed that all three ILs were almost equally active for the synthesis of DBS; only slight differences in the reaction courses were observed for di(2ethylhexyl) succinate (DEHS). All the studied ILs are characterised with a good thermal stability $\left(T_{d}>200{ }^{\circ} \mathrm{C}\right)$, which makes them suitable for this reaction [28]. Based on the respective commodity prices of triethylamine and sulphuric acid, if more sulfuric acid is introduced to the structure of the IL then it will be less expensive. Additionally, all of the studied ILs are characterised with a good thermal stability $\left(T_{\mathrm{d}}>200{ }^{\circ} \mathrm{C}\right)$, which makes them suitable for this reaction [28]. Therefore, based on the ILs' prices, the IL 3.0 would be the least expensive among the three investigated. However, it was observed that IL 3.0 changes its colour while exposed to $70^{\circ} \mathrm{C}$ for several hours, turning slightly brownish, consequently affecting the colour of the final product. This behaviour was not observed for the IL 2.7, which appeared more heat resistant. Another important factor for consideration is the phase separation after the reaction. When IL 2.0 was used, the reaction phases were separated but the $\mathrm{pH}$ of the upper ester phase was slightly acidic, implying that traces of sulfuric acid or ILs were trapped there. On the other hand, IL 2.7 caused sharp phase separation and the $\mathrm{pH}$ of the ester layer was almost neutral. Based on this information, the most convenient IL for esterification of succinic acid is IL 2.7, which is hydrophilic enough for efficient phase separation, acidic enough to achieve high activity and stable during mixing at $70{ }^{\circ} \mathrm{C}$.

In the next step, the influence of the amount of IL 2.7, ranging from 5 to $30 \mathrm{~mol} \% / \mathrm{mol}$ acid, was studied for the synthesis of DBS, DEHS, di-n-butyl adipate DBA and di(2ethylhexyl) adipate DEHA (Figure 2). The results showed that $5 \mathrm{~mol} \%$ of IL was insufficient to overcome the equilibrium of esterification and the ester yields were low, about $80 \pm 3 \%$. Higher amounts of IL (above $10 \mathrm{~mol} \%$ ) are sufficient to obtain almost stochiometric amounts of esters, after the adequate time (90-240 $\mathrm{min})$. Reaction times are generally shorter for di(2-ethylhexyl) esters due to the higher lipophilicity of the resulting esters and, as a consequence, lower phase mixability. As a result of these studies, $15 \mathrm{~mol} \%$ was selected as the optimum amount of IL for the further experiments.

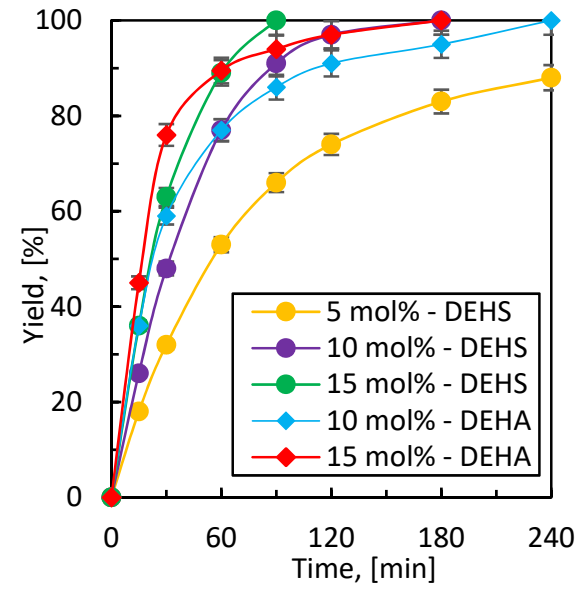

(a)

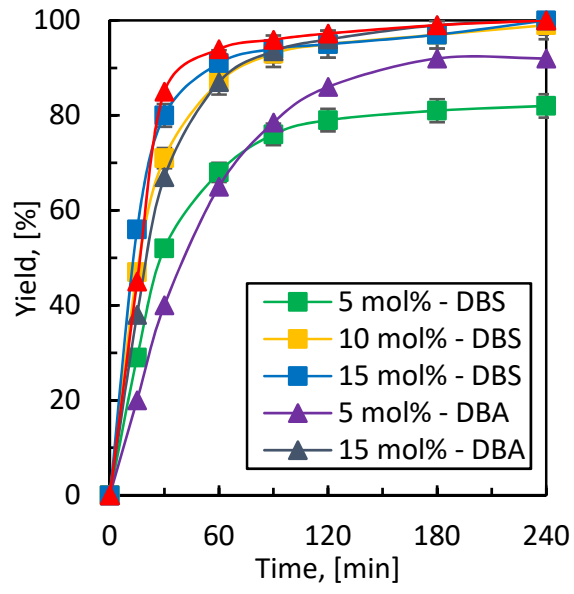

(b)

Figure 2. The influence of the amount of IL 2.7 on the on the esterification of succinic and adipic acid with (a) butan-1-ol and (b) 2-ethylhexan-1-ol. Reaction conditions: alcohol 4 mol; acid 1 mol; $70{ }^{\circ} \mathrm{C}$ (DBS, DEHS); $80{ }^{\circ} \mathrm{C}$ (DBA, DEHA); $17 \mathrm{~Hz}$.

An important parameter, which can influence the esterification reaction yield, is the proportion of alcohol. To test how this will affect the reaction, excesses of 2 to $5 \mathrm{~mol}$ of alcohol per $1 \mathrm{~mol}$ of acid were studied (Figure 3). The results demonstrated that when an increasing excess of alcohol was used, higher yields were found, but only to a point. This is clearly visible with DBS (blue bars, Figure 3a), where a 2:1 ratio allowed us to obtain a yield 
of only $60 \pm 2 \%$. When a 3:1 ratio was applied, this yield increased to $95 \pm 2 \%$ but did not change much with a further increase of the ratio to $4: 1$. Similar results were obtained for the other studied esters (Figure 3b).

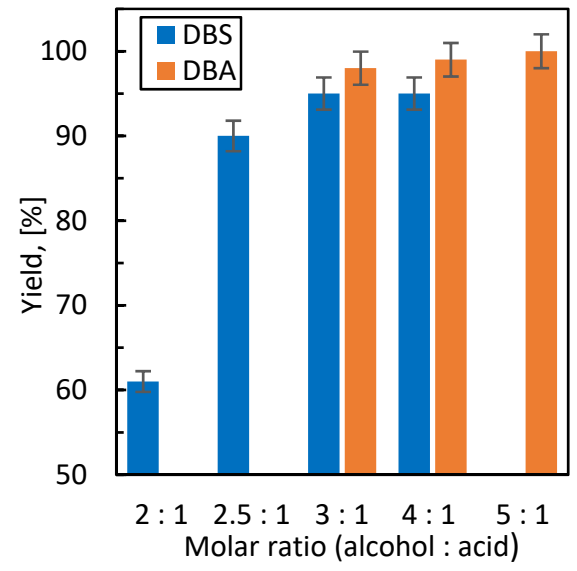

(a)

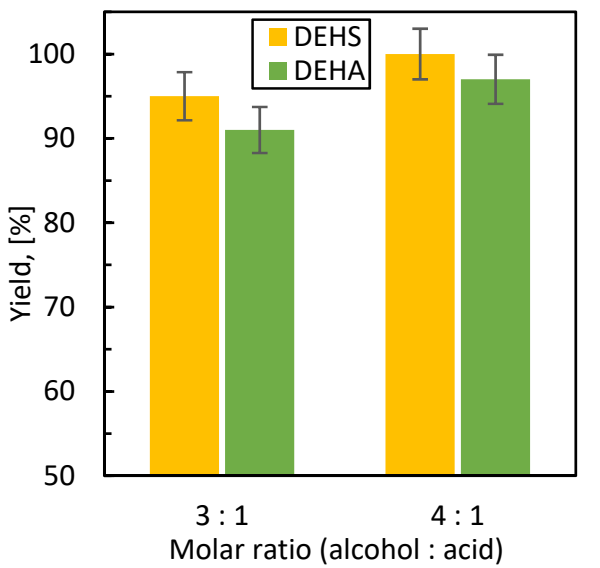

(b)

Figure 3. The influence of the amount of alcohol on the on the esterification of succinic and adipic acid with (a) butan-1-ol and (b) 2-ethylhexan-1-ol. Reaction conditions: acid $1 \mathrm{~mol}$; IL 2.7 (15 mol\%/mol succinic acid (0.0025 mol)); $60{ }^{\circ} \mathrm{C}$ (DBS, DEHS); $80{ }^{\circ} \mathrm{C}$ (DBA, DEHA); $17 \mathrm{~Hz}$; reaction time for (a) $240 \mathrm{~min}$, for (b) $120 \mathrm{~min}$.

The influence of temperature was studied to determine the yield of esterification after $120 \mathrm{~min}$. A series of experiments was performed at $40,50,60,70$ and $80^{\circ} \mathrm{C}$. As expected, the ester yield increased with the temperature (Figure 4). Based on these results it can be concluded that it is favourable to carry out the reaction at $70{ }^{\circ} \mathrm{C}$ for the dialkyl succinates and at $80{ }^{\circ} \mathrm{C}$ for dialkyl adipates.

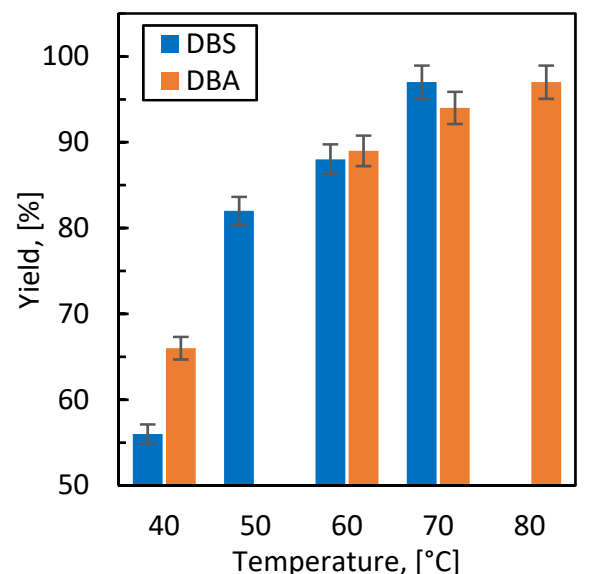

(a)

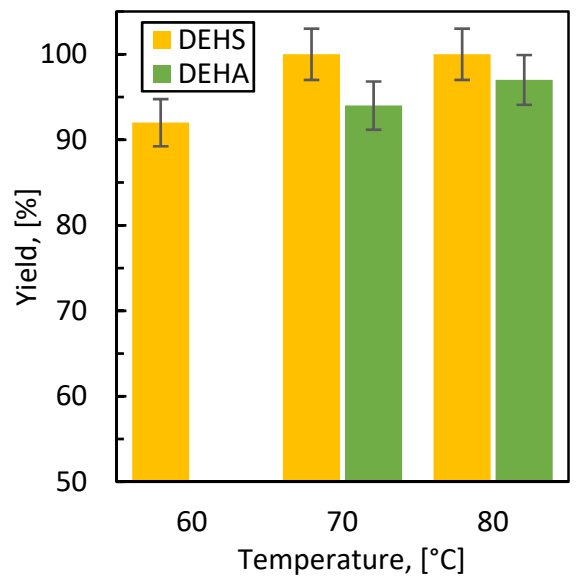

(b)

Figure 4. The influence of the temperature on the on the esterification of succinic and adipic acid with (a) butan-1-ol and (b) 2-ethylhexan-1-ol. Reaction conditions: alcohol 4 mol; acid 1 mol; IL 2.7 $(15 \mathrm{~mol} \% / \mathrm{mol}$ succinic acid $(0.0025 \mathrm{~mol})) ; 17 \mathrm{~Hz}$; reaction time $120 \mathrm{~min}$.

Another important parameter for industrial application is the stability of the catalyst and the possibility of its further reuse in following processes. In order to test stability, a recycle study was performed. IL 2.7 was tested in ten (10) consecutive cycles for the synthesis of DEHS (blue bars, Figure 5) and DEHA (orange bars, Figure 5). After each cycle, the post reaction two-phase mixture was separated and the lower phase (containing mainly IL) was dried using rotary evaporator and used for the next cycle. The percent 
recovery of IL was high (99\%), while the colour of ILs did not visibly change after 10 cycles. The ester-containing upper layer was dissolved in acetonitrile and analysed using GC-FID. As shown in Figure 5, the IL was stable and active in ten reaction cycles, measured by the yield ( $99 \pm 1 \%$ ) and selectivity $(99 \pm 1 \%$ ) of the products.

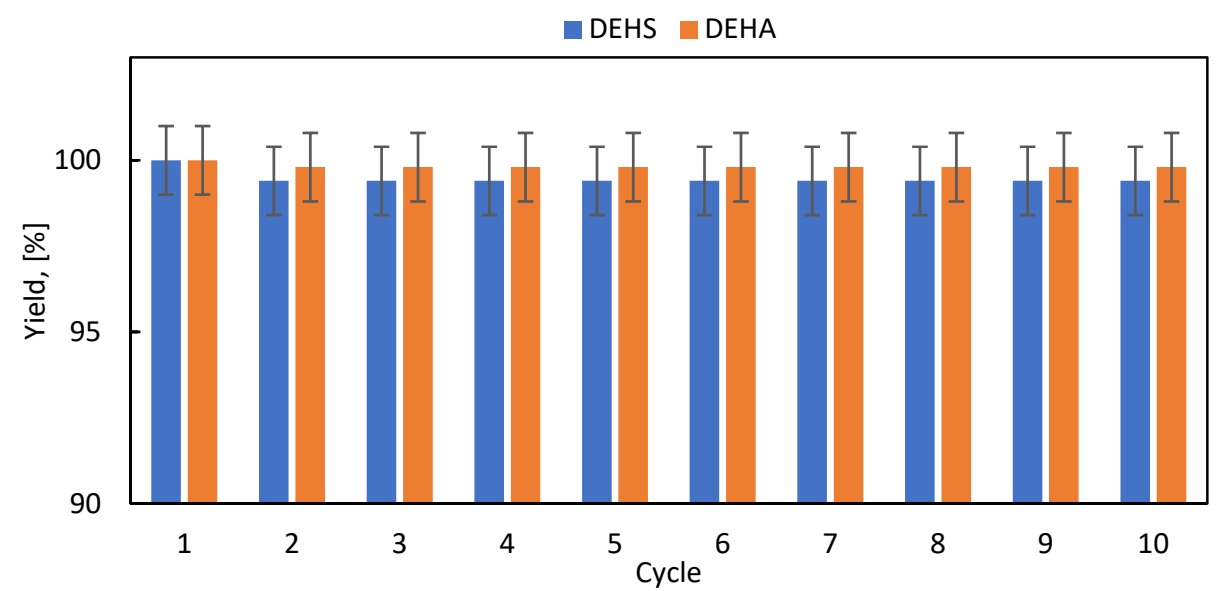

Figure 5. Recycle studies. Reaction conditions: IL 2.7 (15 mol\%/mol succinic acid (0.0025 mol)); alcohol $4 \mathrm{~mol}$; acid $1 \mathrm{~mol} ; 80^{\circ} \mathrm{C}$ (DEHS); $80^{\circ} \mathrm{C}$ (DEHA), $17 \mathrm{~Hz}$; reaction time $240 \mathrm{~min}$.

After each cycle, the post reaction two-phase mixture was separated, the lower phase (mainly containing IL) was dried on the rotary evaporator and used for the next cycle. The upper layer containing ester was dissolved in acetonitrile and analysed using GC-FID. GC samples were analysed in triplicate and the errors were calculated as standard deviations.

\section{Conclusions}

In the pursuit of an effective method which is sustainable and combines the aspects of green chemistry with economic efficiency, we have studied the esterification of succinic and adipic acid with the alcohols butan-1-ol and 2-ethylhexan-1-ol in the presence of acidic IL. The IL was formed via a simple mixing of inexpensive triethylamine and sulphuric $\operatorname{acid}(\mathrm{V})$ with a small addition of water.

Currently, the problem of the development of alternative plasticizers is particularly weighty. The elaborated and cross-verified method overcomes some issues for the synthesis of plasticizers based on the dicarboxylic acids. The advantage of the described method is founded on the application of mild reaction conditions: $70-80{ }^{\circ} \mathrm{C}$, using molar ratio of alcohol to acid 4:1 and only $15 \mathrm{~mol} \%$ of catalyst. Moreover, the isolation of the product via a simple phase separation and alcohol distillation provides high purity of the final ester (>99\%). The separated IL phase, after drying, can be recycled more than 10 times without any sacrifice in activity. It is worth emphasizing that the presence of monoesters has been not detected. These characteristics make this method extensively useful for industrial practice in the future.

The innovative method for the synthesis of dialkyl succinates and adipates presented in the article allows for solutions to some problems resulting from the use of conventional acids in the industrial production of these substances, such as toxicity, high temperatures and harmful waste. Additionally, the ionic liquids used in the tests are characterized by high acidity, high catalytic activity and stability under reaction conditions and their application potential underlines the simplicity of synthesis, easy separation from the reaction mixture, low price and the possibility of recycling to the next reaction cycle.

\section{Patents}

The following patent is the result of the described in this work studies: Chrobok, A.; Erfurt, K.; Latos, P.; Serwata, N.; Grymel, A.; Siwik, B.; Potajczuk-Czajka, K.; Grzybek, R. Process for preparing dialkyl succinates, From Pol. 2020, PL 234515 B1 20200331. 
Author Contributions: Conceptualization, A.C.; methodology, N.B., J.W., P.L., K.E. and A.T.; validation, N.B. and J.W.; formal analysis, P.L. and K.E.; investigation, N.B. and J.W.; data curation, N.B. and J.W.; writing-original draft preparation, A.C., S.B. and K.M.; visualization, A.C. and N.B.; supervision, A.C., E.P. and S.B.; funding acquisition, E.P. and A.T. All authors have read and agreed to the published version of the manuscript.

Funding: This research was funded by the company Grupa Azoty Zakłady Azotowe Kędzierzyn S.A. POIR.01.01.01-00-1166/19.

Institutional Review Board Statement: Not applicable.

Informed Consent Statement: Not applicable.

Conflicts of Interest: The authors declare no conflict of interest.

\section{References}

1. Wypych, G. Handbook of Plasticizers, 3rd ed.; ChemTec Publishing: Toronto, ON, Canada, 2004; pp. 591-613.

2. Bui, T.T.; Giovanoulis, G.; Cousins, A.P.; Magnér, J.; Cousins, I.T.; Wit, C.A. Human exposure, hazard and risk of alternative plasticizers to phthalate esters. Sci. Total Environ. 2016, 541, 451-467. [CrossRef]

3. Jamarani, R.; Erythropel, H.C.; Nicell, J.A.; Leask, R.L.; Marić, M. How green is your plasticizer? Polymers 2018, 10, 834. [CrossRef] [PubMed]

4. Mazitova, A.K.; Aminova, G.K.; Vikhareva, I.N. Designing of green plasticizers and assessment of the effectiveness of their use. Polymers 2021, 13, 1761. [CrossRef]

5. Stuart, A.; Fan, D.; McCallum, M.M.; Mohanty, D. Poly(vinyl chloride) plasticized with succinate esters: Synthesis and characterization. Polym. Bull. 2010, 65, 589-598. [CrossRef]

6. Chaudhary, B.I.; Nguyen, B.; Smith, P.; Sunday, N.; Luong, M.; Zamanskiy, A. Synthesis and properties of a bio-based PVC plasticizer derived from lactic acid. Polym. Eng. Sci. 2015, 55, 634-640. [CrossRef]

7. Iwata, H.; Shimada, K. Formulas, Ingredients and Production of Cosmetics; Springer: Tokyo, Japan, $2013 ;$ p. 181.

8. Zeikus, J.G.; Jain, M.K.; Elankovan, P. Biotechnology of succinic acid production and markets for derived industrial products. Appl. Microbiol. Biotechnol. 1999, 51, 545-552. [CrossRef]

9. Li, K.-T.; Wang, C.-Y. Succinic acid esterification on mixed oxides with titanium. Chem. Eng. Commun. 2016, 203, 1641-1647. [CrossRef]

10. Reinecke, H.; Navarro, R.; Pérez, M. Plasticizers. In Encyclopedia of Polymer Science and Technology; John Wiley and Sons: Hoboken, NJ, USA, 2011. [CrossRef]

11. Chiellini, F.; Ferri, M.; Morelli, A.; Dipaola, L.; Latini, G. Perspectives on alternatives to phthalate plasticized poly(vinyl chloride) in medical devices applications. Prog. Polym. Sci. 2013, 38, 1067-1088. [CrossRef]

12. Chan, K.-W.; Tsai, Y.-T.; Lin, H.-M.; Lee, M.-J. Esterification of adipic acid with methanol over Amberlyst 35. J. Taiwan Inst. Chem. Eng. 2010, 41, 414-420. [CrossRef]

13. Hočevar, B.; Prašnikar, A.; Huš, M.; Grilc, M.; Likozar, B. $\mathrm{H}_{2}$-free re-based catalytic dehydroxylation of aldaric acid to muconic and adipic acid esters. Angew. Chem. Int. Ed. 2021, 60, 1244-1253. [CrossRef]

14. Arpe, H.J. Industrial Organic Chemistry, 5th ed.; Wiley-VCH: Weinheim, Germany, 2010.

15. Yuan, B.; Wang, Y.; Wang, M.; Gou, G.; Li, L. Metal organic frameworks as recyclable catalysts for efficient esterification to synthesize traditional plasticizers. Appl. Catal. A Gen. 2021, 622, 118212-118220. [CrossRef]

16. Jing, C.; Jinhua, L.; Zhongxie, D.; Yuehua, W.; Zhen, L.; Min, J.; Xiaoqian, R. Lewis acid sites of Mg ${ }^{2+}$-modified polystyrene sulfonic acid resin catalysys for synthesis of dibutyl succinate. Quim. Nova 2018, 41, 613-618. [CrossRef]

17. Kim, H.; Kim, T.; Choi, N.; Kim, B.H.; Oh, S.-W.; Kim, I.-H. Synthesis of diethylhexyl adipate by Candida antarctica lipasecatalyzed esterification. Process Biochem. 2019, 78, 58-62. [CrossRef]

18. Ji, X.; Chen, Y.; Shen, Z. Nano-SO ${ }_{4}{ }^{2-} / \mathrm{TiO}_{2}$ catalyzed eco-friendly esterification of dicarboxylic acids. Asian J. Chem. 2014, 26, 5769-5772. [CrossRef]

19. Ding, B.; Xue, L.; Miao, N. Preparation of dibutyl succinate using acid activated bentonite as catalyst. China Surfactant Deterg. Cosmet. 2006, 5, 337-340.

20. Amarasekara, A.S. Acidic ionic liquids. Chem. Rev. 2016, 116, 6133-6183. [CrossRef]

21. Dong, B.; Song, H.; Zhang, W.; He, A.; Yao, S. Ionic liquids as heterogeneous and homogeneous catalysts for condensation and esterification reactions. Curr. Org. Chem. 2016, 20, 2894-2910. [CrossRef]

22. Estager, J.; Oliferenko, A.A.; Seddona, K.R.; Swadźba-Kwaśny, M. Chlorometallate(iii) ionic liquids as Lewis acidic catalysts ca quantitative study of acceptor properties. Dalton Trans. 2010, 39, 11375-11382. [CrossRef] [PubMed]

23. Yoshizawa, M.; Xu, W.; Angell, C.A. Ionic liquids by proton transfer: Vapor pressure, conductivity, and 395 the relevance of $\Delta \mathrm{pKa}$ from aqueous solutions. J. Am. Chem. Soc. 2003, 125, 15411-15419. [CrossRef]

24. Radai, Z.; Kiss, N.Z.; Keglevich, G. An overview of the applications of ionic liquids as catalysts and additives in organic chemical reactions. Curr. Org. Chem. 2018, 22, 533-556. [CrossRef] 
25. Vafaeezadeh, M.; Alinezhad, H. Brönsted acidic ionic liquids: Green catalysts for essential organic reactions. J. Mol. Liq. 2016, 218, 95-105. [CrossRef]

26. Chiappe, C.; Rajamania, S.; D'Andreab, F. A dramatic effect of the ionic liquid structure in esterification reactions in protic ionic media. Green Chem. 2013, 15, 137-143. [CrossRef]

27. Chen, L.; Sharifzadeh, M.; Dowell, N.M.; Welton, T.; Shah, N.; Hallett, J.P. Inexpensive ionic liquids: $\left[\mathrm{HSO}_{4}\right]^{-}$-based solvent production at bulk scale. Green Chem. 2014, 16, 3098-3106. [CrossRef]

28. Matuszek, K.; Chrobok, A.; Coleman, F.; Seddon, K.R.; Swadźba-Kwaśny, M. Tailoring ionic liquid catalysts: Structure, acidity and catalytic activity of protonic ionic liquids based on anionic clusters, $\left[\left(\mathrm{HSO}_{4}\right)\left(\mathrm{H}_{2} \mathrm{SO}_{4}\right)_{\mathrm{x}}\right]^{-}(\mathrm{x}=0,1$, or 2). Green Chem. 2014, 16, 3463-3471. [CrossRef]

29. Gutmann, V. The Donor-Acceptor Approach to Molecular Interactions; Plenum Press: New York, NY, USA, 1978; p. 595. [CrossRef]

30. Przypis, M.; Matuszek, K.; Chrobok, A.; Swadźba-Kwaśny, M.; Gillner, D. Inexpensive and tuneable protic ionic liquids based on sulfuric acid for the biphasic synthesis of alkyl levulinates. J. Mol. Liq. 2020, 308, 113166-113173. [CrossRef]

31. Grymel, A.; Latos, P.; Matuszek, K.; Erfurt, K.; Barteczko, N.; Pankalla, E.; Chrobok, A. Sustainable method for the synthesis of alternative Bis(2-Ethylhexyl) terephthalate plasticizer in the presence of protic ionic liquids. Catalysts 2020, 10, 457. [CrossRef]

32. Dorosz, U.; Barteczko, N.; Latos, P.; Erfurt, K.; Pankalla, E.; Chrobok, A. Highly efficient biphasic system for the synthesis of alkyl lactates in the presence of acidic ionic liquids. Catalysts 2020, 10, 37. [CrossRef]

33. Matuszek, K.; Brzęczek-Szafran, A.; Kobus, D.; MacFarlane, D.R.; Swadźba-Kwaśny, M.; Chrobok, A. Protic ionic liquids based on oligomeric anions $\left[\left(\mathrm{HSO}_{4}\right)\left(\mathrm{H}_{2} \mathrm{SO}_{4}\right)_{\mathrm{x}}\right]^{-}(\mathrm{x}=0,1$, or 2$)$ for a clean $\epsilon$-caprolactam synthesis. Aust. J. Chem. 2019, 72, 130-138. [CrossRef] 